\title{
WARM VERSUS COLD INTERMITTENT BLOOD CARDIOPLEGIA FOR MYOCARDIAL PROTECTION DURING ON-PUMP CORONARY ARTERY BYPASS GRAFTING
}

\author{
Ahmed Hassouna ${ }^{1}$, Ahmed Abdel Aziz', Ayman Mahmoud Amar ${ }^{1}$, Waleed Ismail \\ Kamel $^{l}$ and Hosam Ahmed Mohamed Ahmed ${ }^{2}$.
}

Cardiovascular \& Thoracic

Surgery department, Faculty of medicine, Ain Shams

University,

\section{Corresponding Author:}

Hosam Ahmed Mohamed

Mobile

E-mail:

Received: 30/6/2020

Accepted: 22/7/2020

Online ISSN: 2735-3540

\begin{abstract}
:
Background: Obtaining an optimal surgical result depends on performing a technically proficient operation while protecting the heart from potential damage. Cardioplegia is an essential component in myocardial protection during aortic cross-clamping and cardiopulmonary bypass. The development of cardioplegia solutions is one of the major advances in cardiac surgery that allowed surgeons to extend the period of ischemic arrest to well over 3 hours to perform complex surgical procedures without adversely affecting myocardial functio'.
\end{abstract}

Aim of the work: We sought to compare between two specific modalities of myocardial protection using either intermittent antegrade cold blood cardioplegia or warm blood cardioplegia.

Patients and Methods: This prospective study included 200 successive adult patients who have undergone elective on-pump coronary artery bypass grafting $(C A B G)$ operations. Randomization was done immediately before the beginning of the operation so that group allocation was blinded to the patient. Participants were recruited between 14 January 2017 and 10 July 2019 at Mahalla Cardiac Center. All patients were thoroughly evaluated preoperatively, intraoperatively, and postoperatively.

Results: There was no statistically significant difference between the two groups as regards bypass and cross clamp times. However, there was a statistically significant difference between the two groups as regards spontaneous defibrillation. There were no significant differences in both groups regarding the needed either inotropic support, or an IABP to achieve weaning. The total period of mechanical ventilation was statistically shorter in the warm group compared to the cold group.

Conclusion: We found that there was no difference in the clinical effect of warm or cold blood cardioplegia despite the relative increase in postoperative serum cTnI in the warm cardioplegia group. Both strategies appear to allow a comparable and satisfactory method for myocardial protection during the period of cardiac arrest.

Key words: Cardioplegia, Coronary artery bypass grafting, cardiac markers. 


\section{INTRODUCTION:}

Obtaining an optimal surgical result depends on performing a technically proficient operation while protecting the heart from potential damage. Cardioplegia is an essential component in myocardial protection during aortic cross-clamping and cardiopulmonary bypass. The development of cardioplegia solutions is one of the major advances in cardiac surgery that allowed surgeons to extend the period of ischemic arrest to well over 3 hours to perform complex surgical procedures without adversely affecting myocardial function ${ }^{(1)}$.

It is logical that administering cardioplegia at a cold temperature would be a significant factor in decreasing myocardial metabolism. However, the reduction in myocardial metabolism attributable to hypothermia is actually quite insignificant compared with that achieved by diastolic arrest. Nonetheless, systemic hypothermia supplemented by use of topical cold saline and topical cooling devices that surround the left ventricle and protect the phrenic nerve from cold injury are routinely used in patients receiving cold cardioplegia ${ }^{(2)}$.

Since enzymatic and cellular reparative processes function better at normothermia, some surgeons use warm cardioplegia for myocardial protection with excellent results. However, because of the tendency for the heart to resume electrical activity at normothermia, this must be given continuously or with brief interruptions ${ }^{(3)}$. During routine elective operations in patients with good ventricular function, cardioplegic arrest is done with cold blood cardioplegia. If ventricular function is impaired or there is active ischemia, induction is carried out with warm cardioplegia. If the heart is arrested with a warm induction, low potassium non enriched cardioplegia is then given to cool the heart. Temperature is always monitored in the septum to assure optimal cooling. Warmblood cardioplegia given initially (induction) limits reperfusion damage in ischemic hearts $^{(4)}$.

\section{AIM OF THE WORK:}

The aim of this work was to compare between two specific modalities of myocardial protection using either intermittent ante-grade cold blood cardioplegia or warm blood cardioplegia.

\section{PATIENTS AND METHODS:}

This prospective study included 200 successive adult patients who have undergone elective on-pump coronary artery bypass grafting (CABG). Randomization was done immediately before the beginning of the operation so that group allocation was blinded to the patient. Participants were recruited between 14 January 2017 and 10 July 2019 at Mahalla Cardiac Center. The enrolled patients in our study were divided into two equal groups according to the selected method of myocardial protection. All patients were thoroughly evaluated preoperatively, intraoperatively, and postoperatively.

Group I included 100 patients who received intermittent cold blood cardioplegia every 30-35 minutes; however, Group II included 100 patients who received intermittent warm blood cardioplegia every 10-15 minutes with controlled reperfusion for 3 minutes before aortic unclamping.

The study protocol was approved by the Institution's Ethical Committee/Institutional Review Board and informed consent was obtained from each patient. The study protocol conforms to the human ethical guidelines. All patients were consented about the study and were informed that it carries no additional risk on them. 
Our inclusion criteria were patients with coronary artery disease who have undergone conventional elective on-pump coronary artery bypass grafting and received either warm or cold intermittent blood cardioplegia. However, the exclusion criteria included other methods of myocardial protection, off-Pump CABG, on-pump beating $\mathrm{CABG}$, ejection fraction less than $30 \%$, other comorbidities as: severe decompensated liver, respiratory disease or renal failure, redo cases, emergency cases, patients with recent infarction in the last month as well as patients with other cardiac or extra-cardiac pathologies warranting intervention as valvular intervention or carotid endarterectomy.

Blood samples for determination of the serum levels of creatine kinase (CK) were withdrawn at arrival in the intensive care unit, and troponin-I levels were taken at 6 ,12, 24, and 48 hours after aortic unclamping. Electrocardiographic tracings were obtained the day before operation and immediately after arrival in the intensive care unit. The diagnosis of perioperative myocardial infarction was based on development of new pathological Q wave or disappearance of $R$ wave on the postoperative electrocardiographic tracing and elevation of cTn values of more than 10 times the 99th percentile upper reference limit in patients with normal baseline cTn values $^{(5)}$.

\section{Statistical analysis:}

Variables were presented as means + SD or as numbers and proportions, as appropriate. The relations between qualitative variables were evaluated by Chisquare test or Fisher's exact test, as indicated. Means were compared with Student's test. Variables with $\mathrm{P}$ values $<0.05$ in univariate analysis were introduced in a logistic regression model to detect independent predictors of cardioplegia. All tests were bilateral and a $\mathrm{P}$ value of $5 \%$ was the limit of statistical significance. Repeated measure ANOVA was done to test the effect of time and groups of cardiplegia on troponine level. All analyses were done using SPSS for windows, version 21 (SPSS, Inc., Chicago, IL, USA) with the significance level set at $\mathrm{p}<0.05$.

\section{RESULTS:}

Preoperative risk factors for IHD and demographic data were comparable in both groups expect for hypertension and smoking (Table 1). Left main disease was found in 16 patients in group I and 22 patients in group II. The preoperative echocardiographic data of both groups are summarized in table (1). The mean value for ejection fraction and the end systolic diameter were higher in the warm blood cardioplegia group (II) than cold blood cardioplegia group (I), while the end diastolic diameter was higher in group I than group II. The overall preoperative myocardial function of both groups was within the normal range.

\section{Intraoperative data:}

There was no statistically significant difference between the two groups as regards bypass and cross clamp times. However, there was a statistically significant difference between the two groups as regards spontaneous defibrillation (52 patients in Group I versus 90 patients in Group П). Number of bypass grafts was 2.8 \pm 0.5 for group I and $2.7 \pm 0.9$ for group II with no statistically significant difference between the two groups $(p=0.15)$. It is worth mentioning that there were no significant differences in both groups regarding the needed either inotropic support, or an IABP to achieve weaning.

\section{ICU data:}

Postoperative blood transfusion was comparable in both groups. There was no statistical significance as regards reopening for bleeding. Also there was no significant 
difference between 2 groups as regards duration of ICU stay. The total period of mechanical ventilation was statistically shorter in the warm group compared to the cold group.

\section{Cardiac enzymes after surgery:}

Serum samples for cardiac enzyme CK were taken immediately postoperative, and troponin I serum samples were taken at 6, 12, 24 and 48 hours after arrival to ICU. As regards CK enzyme, there was a statistically significant difference between the two groups, with the lower level in cold cardioplegia Group (I). Furthermore , Troponin I release was significantly higher in warm cardioplegia Group (II) at 12, 24 and 48 hours postoperatively.
There was no statistically significant difference between the two groups as regards postoperative complications. Hospital stay in days was $(9.3 \pm 2.0$ vs. $8.93 \pm 1.70$ ), for group I and II, respectively, (P 0.161).

A logistic regression was used to detect the independent predictors of myocardial preservation as well as morbidity and mortality. These independent predictors include troponine level at 12 and 24 hours, post-operative CK level, ventilation time and spontaneous defibrillation on the likelihood that participants received warm cardioplegia. All variables were significant predictors except troponine level at 24 hours. The model explained $38.5 \%$ (Nagelkerke R2) of the variance and correctly classified $70.5 \%$ of cases (Table 1) .

Table (1) : Patients' demographic data

\begin{tabular}{|c|c|c|c|}
\hline & Group I & Group II & \multirow[t]{2}{*}{ P-value } \\
\hline & $(\mathrm{N}=100)$ & $(\mathrm{N}=100)$ & \\
\hline Age (Years) & $55.92 \pm 7.62$ & $55.60 \pm 7.89$ & 0.66 \\
\hline \multicolumn{4}{|l|}{ Sex } \\
\hline Males & 90 & 86 & \multirow[t]{2}{*}{0.32} \\
\hline Females & 10 & 14 & \\
\hline Diabetes & 55 & 63 & 0.314 \\
\hline Hypertension & 63 & 30 & $<0.001 * *$ \\
\hline Smoking & 25 & 40 & $0.034 *$ \\
\hline Previous MI & 49 & 54 & 0.569 \\
\hline LMCA disease (>50\%) & 16 & 22 & 0.368 \\
\hline BMI & $26.296 \pm 4.9984$ & $26.458 \pm 4.5438$ & 0.633 \\
\hline Mean EF (\%) & $59.160 \pm 6.0924$ & $61.185 \pm 5.8753$ & $<0.001^{* * *}$ \\
\hline Average NYHA class & $2.64 \pm 0.7$ & $2.4 \pm 0.89$ & 0.074 \\
\hline $\mathrm{EF}$ & $63.210 \pm 6.0924$ & $59.160 \pm 5.8753$ & $<0.001^{* *}$ \\
\hline $\mathrm{ESD}(\mathrm{mm})$ & $48.910 \pm 1.2152$ & $39.219 \pm 9.0999$ & $<0.001 * *$ \\
\hline EDD (mm) & $59.980 \pm 0.3172$ & $51.460 \pm 7.2952$ & $<0.001^{* *}$ \\
\hline ESPAP (mmhg) & $15.080 \pm 2.3254$ & $15.100 \pm 2.2585$ & 0.951 \\
\hline Preop. $\mathrm{Hb}(\mathrm{gm} \%)$ & $12.890 \pm 1.5052$ & $13.726 \pm 1.1342$ & 0 \\
\hline S. creatinine $(\mathrm{mg} \%)$ & $0.918 \pm 0.2694$ & $0.849 \pm 0.2329$ & 0.054 \\
\hline SGPT (IU/dl) & $13.210 \pm 3.3973$ & $13.420 \pm 3.2355$ & 0.655 \\
\hline Preop cTnI ( $\mu / \mathrm{ML})$ & $0.03657 \pm .029579$ & $0.04168 \pm 0.031022$ & 0.235 \\
\hline Hyperlipidemia & 37 & 43 & 0.471 \\
\hline
\end{tabular}


Table (2): Hospital outcome

\begin{tabular}{|l|l|l|l|}
\hline & $\begin{array}{l}\text { Group I } \\
(\mathrm{N}=100)\end{array}$ & $\begin{array}{l}\text { Group II } \\
(\mathrm{N}=100)\end{array}$ & P-value \\
\hline Total bypass time (min.) & $67.570 \pm 22.6726$ & $72.550 \pm 21.4991$ & 0.113 \\
\hline Cross clamp time (min.) & $45.08 \pm 16.1868$ & $47.57 \pm 13.8354$ & 0.244 \\
\hline Average Distal Anastomoses & $2.73 \pm 1.51$ & $3 \pm 1.35$ & 0.185 \\
\hline Spontaneous defibrillation & 52 & 90 & $0.0001^{*}$ \\
\hline Use of inotropic support & 28 & 24 & 0.629 \\
\hline Use of IABP & 9 & 6 & 0.593 \\
\hline Intraop. blood transfusion. & 0 & 4 & 0.121 \\
\hline Perioperative MI. & 1 & 1 & 1 \\
\hline Haemorhage $(\mathrm{ml})$ & $567.40 \pm 245.6721$ & $515.97 \pm 218.1225$ & 0.119 \\
\hline Reopening $($ count). & 0 & 2 & 0.497 \\
\hline Mechanical ventilation $(\mathrm{Hrs})$. & $9.780 \pm 3.6751$ & $8.050 \pm 3.5430$ & $0.0001^{*}$ \\
\hline ICU stay $($ days) & $2.43 \pm 1.188$ & $2.44 \pm 1.230$ & 0.933 \\
\hline S. creatinine & $1.70 \pm .508$ & $1.61 \pm 1.764$ & 0.622 \\
\hline SGPT & $30.380 \pm 21.2045$ & $28.790 \pm 25.1927$ & 0.63 \\
\hline Hb $(\mathrm{gm} \%)$ & $11.630 \pm 1.9715$ & $11.761 \pm 1.7857$ & 0.623 \\
\hline Postoperative CK level $(\mathrm{IU})$ & $21.330 \pm 14.1057$ & $30.560 \pm 22.0217$ & $0.0001^{*}$ \\
\hline Troponin 6 hrs. $(\mu \mathrm{g} / \mathrm{mL})$ & $0.0919 \pm 0.06804$ & $0.1076 \pm 0.08187$ & 0.142 \\
\hline Troponin 12 hrs. $(\mu \mathrm{g} / \mathrm{mL})$ & $0.139950 \pm 0.1020262$ & $0.172400 \pm 0.1070554$ & $0.029 *$ \\
\hline Troponin 24 hrs. $(\mu \mathrm{g} / \mathrm{mL})$ & $0.199760 \pm 0.1297445$ & $0.230200 \pm 0.1279834$ & 0.096 \\
\hline Troponin 48 hrs. $(\mu \mathrm{g} / \mathrm{mL})$ & $0.027260 \pm 0.0363525$ & $0.062660 \pm 0.0815285$ & $0.0001 *$ \\
\hline Wound infection & 0 & 5 & 0.059 \\
\hline AF & 23 & 18 & 0.484 \\
\hline Stroke & 1 & 1 & 1 \\
\hline Reopening & 0 & 2 & 0.497 \\
\hline Mortality & 1 & 1 & 0.43 \\
\hline EF $(\%)$ & $55.96 \pm 7.35$ & $56.77 \pm 7.23$ & 0.132 \\
\hline ESD & $47.54 \pm 2.94$ & $48.18 \pm 3.04$ & 0.48 \\
\hline EDD & $56.8 \pm 0.63$ & $57.44 \pm 0.64$ & \\
\hline & & & \\
\hline
\end{tabular}

\section{DISCUSSION:}

Myocardial cell injury after cardiac surgery is unavoidable with the currently available hyperkalaemic cardioplegic solutions. Several modifications to the cardioplegic solutions were made to decrease this cellular injury ${ }^{(6)}$. The concept of warm blood cardioplegia was introduced in 1983, based on a study that found that norm-othermic arrested heart requires 80$90 \%$ less oxygen than does the normal working heart and from reports that indicated that 'Hot Shot' has significantly positive effects on myocardial recovery ${ }^{(7,8)}$. The deliberate use of intermittent antegrade warm blood cardioplegia was for the first time reported by Calafiore in a retrospective study ${ }^{(\mathbf{9})}$. It has become the standard of care to administer antegrade blood cardioplegia for $\mathrm{CABG}$ procedures ${ }^{(10)}$.

Cardiac troponin I (cTn I) is one of the biomarkers used for risk assessment of several cardiac diseases and post cardiac surgery. It is released whenever myocardial injury occurs regardless of the mechanism of injury and its release post cardiac surgery was found to be associated with increased morbidity and mortality. Thus, high sensitivity cardiac cTn I is a marker of myocardial injury and it has a prognostic role in several cardiac pathologies and after cardiac surgeries $^{(11)}$.

Baig MA ${ }^{(12)}$ conducted a study on 215 CABG patients. Of the studied patients $94(44 \%)$ were in intermittent antegrade 
warm blood cardioplegia group with a mean age of $54.61 \pm 7.85$ years, and $121(56 \%)$ in cold blood group with a mean age of $53.85 \pm 9.32$ years. Total surgical time in cold blood group was 119.26 \pm 22.24 minutes compared to $105.73 \pm 31.34$ in warm blood cardioplegia group ( $p \quad>0.0001$ ). Spontaneous resumption of sinus rhythm and peri-operative myocardial infarction was statistically insignificant $(\mathrm{p}>0.05)$. There were $21(17.4 \%)$ patients in intermittent antegrade cold blood cardioplegia Group to whom peri-operative myocardial infarction occurred compared to $9(9.6 \%)$ in intermittent antegrade warm blood cardioplegia group $(\mathrm{p}=0.10)$.

The two groups in our study were comparable as regards their demographic characters with the mean age in warm blood cardioplegia group was 57.4 years versus 57.9 years in cold blood group. Also were the sex distribution, the body mass index, and other comorbidities. Thus, the study recruited patients represent a homogeneous sample.

The incidence of diabetes and hypertension in our study was 59\% and $46.5 \%$ respectively. The incidence of hypertension in Jacquet et $\mathrm{al}^{(13)}$ study was $50.5 \%$ which was slightly higher than ours. But in Sirvinskas et $\mathrm{al}^{(14)}$ study there was a percentage of 42.3 of hypertensive patients which was comparable to this study. There was a very high percentage of hypertension in Zeriouh et al. ${ }^{(10)}$ study groups which was $85 \%$. Also, the incidence of diabetes was larger than in Zeriouh study as it was $35.3 \%$. The incidence of smoking in the whole study cohort was $32.5 \%$ compared with $45 \%$ in Elwatidy et $\mathrm{al}^{(15)}$ study, while the incidence of smoking was $43.7 \%$ in Zeriouh study ${ }^{(10)}$.

Coronary angiography revealed that 36 patients in group I had 3 vessels disease, 50 patients had 2 vessels disease and 14 patients had single vessel disease compared to 40 patients in group II with 3 vessels disease, 49 with two vessels disease and 11 with single vessel disease. The incidence of significant LMCAD (> 50\% stenosis) in our study was $38 \%$. The percentage was lower in patients in our study group I (16) but there was no statistically significant difference compared to the group II (22).

Our study data was comparable to Zeriouh et al. ${ }^{(10)}$ who reported an incidence of $32.9 \%$ of LMCAD. Elwatidy et $\mathrm{al}^{(15)}$ reported an incidence of $30.5 \%$ of LMCAD. Dar et $\mathrm{al}^{(16)}$ reported an incidence of $23.3 \%$ of LMCAD. Calafiore ${ }^{(9)}$ Study reported an incidence of $7 \%$ of LMCAD.

Regarding our intraoperative data analysis; there was no statistically significant difference between the two groups as regards bypass and cross clamp times. The average bypass time and cross clamp time in our study was $(67.57 \pm 22.67$ and $45.08 \pm 16.18)$ minutes, and (72.55 \pm 21.49 and $47.57 \pm 13.83)$ minutes for group I and II respectively.

Our results are similar to Martin et al. ${ }^{(17)}$ who reported $86.4 \pm 29.6$ to $83.5 \pm 29.7$ minutes average bypass time, and 39.9 \pm 20.5 to $46 \pm 23.4$ minutes average cross clamp time for an average of three distal anastomoses. Calafiore et $\mathrm{al}^{(9)}$ reported 67.2 \pm 21.3 to $76.3+27.5$ minutes average bypass time, and $45.2 \pm 16.3$ to $44.8 \pm 15.2$ minutes average cross clamp time.

Our results also matches that of Zeriouh et al. ${ }^{(10)}$ who reported $77.96 \pm 25.20$ to $82.93 \pm 32.25$ minutes average bypass time for elective $\mathrm{CABG}$, and $39.92 \pm 12.65$ to $43.96 \pm 15.85$ minutes average cross clamp time. In this study; the parameters used to evaluate the two methods of myocardial preservation were spontaneous defibrillation which indicated the myocardial recovery after de-clamping, the CKMB and cTnI to assess ischemic myocardial injury, the inotropic support, the use of IABP, the ICU stay, the mechanical ventilation, and the mortality rate to reflect the clinical outcome in relation to myocardial protection. 
Spontaneous defibrillation has been used by many surgeon as an indicator of myocardial recovery after a period of cross clamping which could reflect the state of effective myocardial protection ${ }^{(\mathbf{1 8})}$.

In our study the incidence of spontaneous defibrillation was $71 \%$. There was statistically significant difference between the two groups with incidence of spontaneous resumption of sinus rhythm in 90 patients of the warm blood group II compared to 52 patients in cold group I (p $0.0001)$. Jacquet et al. ${ }^{(13)}$ reported $96.2 \%$ spontaneous defibrillation of intermittent warm blood cardioplegia versus $83.6 \%$ in cold group. Elwatidy et al. ${ }^{(15)}$ reported 95.7\% spontaneous defibrillation in warm blood group compared to $2.5 \%$ in cold group. In the study of Christakis et al ${ }^{(\mathbf{1 9})}$, the normothermic patients had a higher incidence of spontaneous defibrillation at cross-clamp removal (64\%) than the hypothermic patients $(33 \%)(\mathrm{p}<0.01)$.

The incidence of spontaneous defibrillation in our study might be due to the application of hot shot of warm blood before de-clamping in the patients in the warm blood group II. The hot shot provides an energy replenishment and recovery of aerobic metabolism resulting in better recovery of function and higher levels of coronary blood flow with slightly better function ${ }^{(11)}$.

Spontaneous cardiac defibrillation at cross-clamp removal is intuitively accepted by surgeons as a "good thing." The absence of fibrillation may result in less high-energy phosphate depletion or less cardiac distention. It is well known that hypothermia alone can cause cardiac fibrillation ${ }^{(\mathbf{1 1})}$.

In Baig and coworkers study ${ }^{(12)}$ : the Aortic cross clamp time in cold blood cardioplegia group was $65.71 \pm 13.58$ minutes versus $62.52 \pm 13.38$ minutes in warm blood group $(\mathrm{p}=0.08)$. Doses of epinephrine on weaning were significantly low in cold blood cardioplegia group $(\mathrm{p}=0.006)$. Frequency of IABP use and post-operative peak CK-MB levels were significantly high in Group II $(\mathrm{p}<0.05)$. IABP was inserted in $14(12.6 \%)$ patients in cold blood cardioplegia group compared to only $4(4.3 \%)$ in warm blood group $(\mathrm{p}=0.03)$. Peak post-operative CK-MB levels in the cold blood group were 106.19 \pm 94.28 IU/L and $70.50 \pm 38.03$ in warm blood group $(p$ $>0.0001)$. There was no difference in the incidence of post operative atrial fibrillation between groups (23 vs. 18) in warm blood group and cold blood group respectively, $(\mathrm{p}$ value 0.3 ). One patient developed postoperative atrial fibrillation, was cardioverted with amiodarone, discharged in sinus rhythm and then found dead at home.

A second patient had poor quality target arteries; she had an intra-aortic balloon pump inserted during surgery, came off bypass with much inotropic support, developed biventricular failure and died despite increasing inotropic support and continuous haemofiltration. A third patient developed complete heart block on the 7 th postoperative day and was treated by inserting a transvenous pacing wire; he subsequently developed renal failure, sepsis, bowel ischaemia and died from multi-organ failure and respiratory arrest.

Twenty eight patients in our group I, and 24 patients in group II needed different doses of inotropic support because of the low cardiac output either intraoperatively or postoperatively ( $\mathrm{p}: 0.62$ ). The incidence of atrial fibrillation was $23 \%$ in group I and $18 \%$ in group II (p: 0.484). There was one case of mortality in each group.

Our data also confirm those by Fan et al. (20) who conducted a meta-analysis of warm versus cold cardioplegia identifying 41 randomized controlled trials with 5,879 patients. The in-hospital mortality, length of stay, incident of stroke, and atrial fibrillation and use of balloon pumps did not differ between groups. However, warm 
cardioplegia was associated with significantly better postoperative cardiac index $(\mathrm{P}<0.00001)$, lower troponin concentrations on day $0(\mathrm{P}=0.006)$, and significantly lower peak CKMB concentrations $(\mathrm{P}=0.002)$. They reported that the concentrations of both cTn and CK-MB were significantly reduced in warm group after surgery, as compared with the cold group. Their results demonstrated that warm cardioplegia was associated with lower postoperative enzyme release, which might indicate less cardiocyte injury $^{(20)}$. The difference of cTn and CK-MB level may be attributed to cardioplegia administration method. Most of the studies included in Fan et al meta-analysis used continuous warm cardioplegia, in contrast to our methodology where we used intermittent cardioplegia to avoid the obscured field by the continuous blood flow.

Mallidi et al ${ }^{(21)}$ performed a prospective single center cohort study comparing patients receiving cold or tepid/warm cardioplegia during isolated CABG on early and late outcomes and found superior outcomes in the warm cardioplegia arm: perioperative death (1.6 versus $2.5 \%, \mathrm{P}$ 0.027 ) and myocardial infarction (2.4 versus $5.4 \%, \mathrm{P}<0.0001)$.

Spontaneous defibrillation is probably not due to temperature alone. There may be a high incidence of spontaneous defibrillation after intermittent cold blood cardioplegia when a terminal hot shot was infused $^{(8,22)}$.

The presence of complete diastolic arrest before cross-clamp removal may also contribute to spontaneous defibrillation. Non-visible micro-fibrillatory cardiac activity may actually be present in hypothermic hearts before cross-clamp removal. Spontaneous defibrillation is probably related to both the extent of diastolic arrest and the core body temperature.

Although the electro-mechanically arrested normo-thermic heart may have low energy requirements, the same cannot be said for myocardium with electrical or mechanical activity. It is therefore important that myocardial activity be closely monitored when employing the warm heart surgery technique. Cardiac activity that occurs during hypothermic cardiopulmonary bypass and intermittent cold blood cardioplegia is probably related to myocardial re-warming from noncoronary collateral flow and possibly poor distribution of cardioplegia distal to the critical coronary stenoses.

In our study 28 patients in group I experienced a need for inotropic support in comparison to 24 patients in group II which was statistically in-significant ( $p$ 0.62). The use of IABP was comparable between the two groups: 9 versus 6 patients in group I and II respectively (P 0.593). Elwatidy et $\mathrm{al}^{(15)}$ reported overall low cardiac output (LCO) of $9.5 \%$ with more percentage among cold group compared to tepid blood group. Also they reported more use of IABP in cold group than tepid bloodgroup.

Jacque et $\mathrm{al}^{(13)}$ reported an incidence of $50 \%$ use of inotropic support and 3.5\% incidence of IABP use. The percentage was higher in cold group but this difference did not reach a statistical significance. Zeriouh and co-workers reported $11 \%$ incidence use of inotropic support in patients who underwent elective $\mathrm{CABG}$ with higher percentage in cold group but without a statistical significance ${ }^{(10)}$.

Calafiore et $\mathrm{al}^{(9)}$ reported statistically significance higher low cardiac output (CO) in patients who received warm blood cardioplegia compared to cold blood cardioplegia. Lichtenstein $^{(18)}$ and coworkers reported low incidence of low $\mathrm{CO}$ in patients receiving warm antegrade blood cardioplegia compared to those who received intermittent cold blood cardioplegia 
Christakis and associates reported a three-fold higher incidence of intraoperative vasopressor support in patients undergoing warm heart operation ${ }^{(19)}$.

Overall, 8 patients $(4 \%)$ underwent early surgical exploration for postoperative mediastinal hemorrhage or tamponade, 6 in the normothermic cardioplegia group and 2 in the cold cardioplegia group. In the two groups, the coagulation factors averaged within normal limits at 1 hour and 24 hours after operation. Postoperative cerebrovascular accidents occurred in 2 patients $(1.5 \%) ; 1$ patient in the normo-thermic group sustained left hemiplegia and aphasia with major permanent neurologic deficits, and 1 patients in the hypothermic group had postoperative transient deficits with no residual impairment. None of these differences between groups were significant.

In our study, the periods of mechanical ventilation, in hours, were longer in the hypothermic group. This difference showed a statistically significant value $(9.7 \pm 3.6$ versus $8.0 \pm 3.5, \mathrm{p}$ 0.001). Similarly, Calafiore and his co-workers, demonstrated in their study significantly longer periods of mechanical ventilation as well as longer ICU stay in patients received cold cardioplegia than those received warm cardioplegia ${ }^{(9)}$.The study of Loop ${ }^{(23)}$ and his co-workers demonstrated that the median length of stay in the intensive care unit, was one day in the normo-thermic group and two days in the hypothermic group, and the length of time spend in the intensive care unit correlates closely with morbidity and hospital stay. Some studies have clearly reported a higher incidence of neurologic events during normo-thermic $\mathrm{CPB}^{(24)}$

However, in our current study two cases of stroke were reported, one patient in each group. The neurological events which may be encountered is some cases, may be related to some extent to the degree of the associated carotid artery disease. It is possible that the high neurologic complication rate seen by Martin and associates was related to the use of a proximal occlusion clamp to complete proximal vein graft anastomosis. In patients with diffuse atherosclerosis involving the ascending aorta, the use of side occlusion clamp may result in embolization of debris to the brain. In this setting patients perfused normo-thermically could likely sustain more damage than those perfused hypothermically ${ }^{(24)}$.

Mauney and Kron reported higher incidence of total neurologic events and perioperative stroke in the warm group. Hyperglycemia, loss of the neuro-protective effects of moderate hypothermia, and embolic phenomena were offered as a possible explanation for the higher stroke rate $^{(25)}$.

The same fact was found in a study by Martin and colleagues, who suggested that normo-thermia increased the neurologic risk of warm heart operations in their prospective randomized trial ${ }^{(17)}$.

Ikonomidis and coworkers found that the incidence of both transient and persistent neurologic deficits was doubled with warm versus cold perfusion in contrast to Toronto prospective randomized trial, which did not demonstrate any difference in the incidence of neurologic complication between the two groups $^{(26)}$.

The central nervous system is particularly vulnerable to damage during warm heart operations. Warm brain is more susceptible to micro-emobilzation or ischemic damage. That's why new protocol for warm cardioplegia have evolved which allow systemic temperature to drift passively to $32^{\circ} \mathrm{C}$ to provide more protection to the brain.

Singh in his study argued that the incidence of stroke is not related to the systemic perfusion temperature. Singh claimed that the neurological event is related more to the preexisting cerebro-vascular 
disease, or some alternation in the surgical techniques that minimize dislodgment of atheromatous debris, also the age of the patients is a very important issue, the stroke rate was approximately four times greater in patient over 70 years of age. This may be due to greater incidence of aortic atherosclerosis $^{(27)}$.

Efforts to reduce neurologic complications of cardiac operations are a priority to maintain patient's quality of life, to maintain patient productivity, and to reduce the overall cost of cardiac surgical care and hospitalization ${ }^{(28)}$.

The use of hyperkalemic blood infused through a side arm of cardiopulmonary bypass, obviates the need for infusing extra fluid to obtain cardioplegic arrest in the normo-thermic group, unlike the cold group in whom more cardioplegic volume is needed with resulting tissue and brain edema. This is not only reflected in the form of delayed recovery of conscious level and hence delayed extubation, but also leads to higher total fluid imbalance in the postoperative period ${ }^{(26)}$.

Sirvinskas et al reported an incidence of $2.5 \%$ of perioperative MI with slightly higher statistically insignificant number in cold group ${ }^{(29)}$. Elwatidy ${ }^{(15)}$ reported $1.6 \%$ incidence of peri-operative $\mathrm{MI}$ in 2 patients who had both endarterectomy for RCA, and both had inferior MI that could related to the endarterectomyprocedure. Franke et $\mathrm{al}^{(30)}$ reported $2.5 \%$ incidence of perioperative MI with no significance between warm blood group and cold blood group.

Zeriouh et al. (10) reported $12 \%$ incidence of perioperative MI in their study with higher statistically insignificant number among warm blood group. This relatively high percentage of perioperative MI may be related to the higher number of the patients in the study (n: 2292), or it could be related to inclusion of many patients with comorbidities, and emergent surgeries.
Bleeding after cardiac operations is an important cause of morbidity and mortality. In our study no difference of statistical significant was observed in the amount of chest tubes drainage in the first 24 hour after surgery in both warm and cold groups. The average amount was $(515.97 \pm 218.12) \mathrm{ml}$ in the warm group and $567.4 \pm 245.67 \mathrm{ml}$ in the cold group ( $\mathrm{p}$ 0.119). Bleeding profile was normal before surgery as well as platelet count in both groups Similarly, in a study performed by Calafiore, blood loss was similar in both normothermic and hypothermic group, with an average amount of $400 \mathrm{cc}$ in the first 12 hour. Also, the number of patients given blood transfusions were similar ${ }^{(9)}$.

Boldt found that postoperative blood loss and the need for homologous blood were higher in the hypothermic than in the normothermic group. Fibrinogen level and platelet count were significantly more reduced during and after cardiopulmonary bypass in the hypothermic than in the normothermic patients. Boldt also observed that approximately $10 \%$ to $20 \%$ of patients undergoing hypothermic perfusion, exhibit inadequate hemostasis and often require homologous blood or blood product transfusion and about 3\% will need reexploration $^{(31)}$.

Yau and his associates found that blood loss was significantly greater in patients having hypothermic bypass compared to patients who underwent normothermic bypass $^{(32)}$. The same findings were encountered also by Vaughn and coworker, they reported $20 \%$ reduction in daily blood loss in patients in whom normothermic bypass was used compared to those in whom hypothermic cardiopulmonary bypass was used $^{(33)}$.

Tonz and his co-worker confirmed the same fact, they found that the volume of blood discharged through the mediastinal and pleural tubes until the first postoperative day, was significantly higher in the 
hypothermic group, and that half of these patients needed fresh-frozen plasma to counteract an increasing bleeding tendency ${ }^{(33)}$. The activation of platelet leads to decreased adhesiveness and reduced membrane binding to fibrinogen, also the increase in fibrinolytic activity with increase of fibrin degradation products may also account for more disturbance in platelet function as these product may interfere with platelet aggregation. All these events are believed to be exacerbated by hypothermic than normo-thermic bypass ${ }^{(34)}$.

Various pharmacological [e.g Aprotonin] and non-pharmacological [e.g pre-donation of autologous blood, cell saver] intervention to reduce blood loss have been advised. Yau in his study found that systemic perfusion at $37 \mathrm{C}$ obviate the need of anti-fibrinolytic to reduce blood loss ${ }^{(35)}$. Boldt in his study demonstrated that platelet count did not differ between warm and cold group, and that the problem was the platelet function. Hypothermia not only disturbs platelet function during cardiopulmonary bypass, but also causes delayed recovery of platelet function in post-operative period ${ }^{(31)}$.

It has become obvious that the endothelium appears to play an important role in the regulation of anti-coagulant pathways. It secretes and express compounds involved in hemostasis, thrombomodulin is one of these substance expressed by endothelial cell, together with protein $\mathrm{C}$ and protein $\mathrm{S}$ system. They play an important role in coagulation cascade. The release of these substances is markedly disturbed in hypothermic than normothermic cardiopulmonary bypass, and this may contribute to bleeding tendency observed more in hypothermic bypass ${ }^{(31)}$.

The average ventilation time and ICU stay in our study were $(9.78 \pm 3.67$ hours and $8.0 \pm 3.54), \quad(2.43 \pm 1.188,2.44 \pm 1.230$ days $)$ for group I and II, respectively. The average ventilation time was less in warm blood group II than group I (P 0.001), but the average ICU stay was comparable in both groups with a statistically insignificant difference ( $p$ 0.93). In accordance with our results, Jacque et $\mathrm{al}^{(13)}$ reported comparable ICU stay between cold and warm blood cardioplegia groups. On contrary, in Calafiore study $^{(36)}$ there was a significant decrease in ICU stay in warm blood cardioplegia group in comparison to cold blood group.

We report a non significant difference regarding the postoperative clinical outcome, haemodynamic recovery, and cardiac function between the two groups. Similarly, one study concluded that warm and cold cardioplegia result in similar shortterm mortality. It also concluded that large studies have shown that warm cardioplegia reduces adverse postoperative events ${ }^{(37)}$. Boening and associates investigated the influence of warm and cold intermittent cardioplegia on cardiac function, metabolism, haemodynamic recovery, structural recovery and infarct size. They came to the conclusion that the two blood cardioplegia solutions offer equally good myocardial protection ${ }^{(38)}$.

Onorati et al found that in patients with warm blood cardioplegia, postoperative cardiac function was improved, the need for transfusions was reduced and the postoperative hospital stay was shorter ${ }^{(39)}$. Hayashi et al described the 'beneficial myocardial protective effects' of a warm solution that corresponded to better LV function, lower creatine kinase-MB levels, and less catecholamine support compared with patients receiving cold solution ${ }^{(40)}$.

The serum total $\mathrm{CK}$, and cTnI were serially measured immediately postoperative, at $6,12,24$ and 48 hours post arrival to ICU. As regards CK, there was no statistical difference between the two groups (immediate arrival in ICU), but there was a highly significant decrease in their release after $24 \mathrm{hrs}$. in warm blood cardioplegia group II in comparison to group 
I . In contrast to CK measures, the decrease of myocardial release of cTnI was highly significant immediately postoperative, 12 , and 24 hours after arrival to ICU. Elwatidy et al. ${ }^{(15)}$ reported significant lower release of CK and CKMB in tepid blood group compared to cold group. Franke et $\mathrm{al}^{(30)}$ study showed significant lower CKMB and cTn release in warm blood group. In a study conducted by $\operatorname{Dar}^{(16)}$, he also reported significant lower release of CKMB and Troponin in patients received antegrade warm blood cardioplegia compared to those who received cold crystalloid cardioplegia. Furthermore, two large meta-analysis studies had similar results as regards postoperative cardiac enzymes release.

Guru and coworkers ${ }^{(41)}$. performed a meta-analysis of 34 randomized clinical trials and reported that there was a significant increase in CK-MB release with cold cardioplegia. Fan and coworkers performed a meta-analysis of 41 randomized clinical trials comparing cold and warm cardioplegia for myocardial protection. They reported that the concentrations of both $\mathrm{cTn}$ and CK-MB were significantly reduced in warm group after surgery. They claimed that warm cardioplegia was associated with lower postoperative enzyme release, which might indicate less cardiocyte injury. Bruyn $^{(42)}$ and coworkers 2014 didn't show any significant difference in CKMB and cTn level between warm and cold groups in patients undergoing either $\mathrm{CABG}$ or valve surgeries. Despite the proposed advantages of warm blood cardioplegia, a warm heart requires $10-20 \%$ more oxygen than a cold heart.

This oxygen demand, though small, may not be neglectable. The warm heart is more susceptible for inhomogeneity in cardioplegic distribution. Ischemia in a warm heart may be the net result ${ }^{(43)}$. In the warm cardioplegic heart an oxygen debt occurs after 3.5 minutes of warm ischaemia. Matsuura $^{(44)}$ and associates reported that interruptions of warm blood cardioplegia for 7- or 10-minute episodes cause ischaemic damage. Warm intermittent cardioplegia is also warm intermittent ischemia. With increasing ischaemic time the result will inevitably be an ischaemic injury ${ }^{(44)}$.

A prospective randomized study comparing intermittent antegrade warm blood cardioplegia with cold cardioplegia by Pelletier and associates showed less release of CK-MB and troponin-T in warm group $^{(45)}$. Also the study of Yau and his colleague demonstrated that the total CKMB release within 48 hours after the operation, was lower after warm blood cardioplegia than cold blood cardioplegia and that peak postoperative CK-MB levels tended to be lower after warm cardioplegia but no statistical significant difference observed $^{(32)}$.

The greater leakage of CK-MB from the cold hearts in these prvious studies implies more extensive myocyte necrosis and more disruption of sarcolemmal integrity, allowing transient transmembrane loss of these high molecular weight proteins which reflects suboptimal myocardial protection ${ }^{(35)}$. Matsuura et $\mathrm{al}^{(44)}$ revealed that interrupting warm blood cardioplegia during coronary revascularization diminished the effect of warm blood cardioplegia. Successive short periods of warm ischemia may predispose to ischemic myocardial injury.

The cause of our relative higher cTn I in warm group may be attributed to the failure of warm cardioplegia to induce rapid myocardial arrest. A higher potassium concentration may be needed to prevent this failure.

Pelletier et $\mathrm{al}^{(45)}$ reported a failure rate of $13 \%$ to achieve sustained electromechanical arrest by use of warm blood cardioplegia. Kaul et al $1989^{(46)}$ on 123 patients undergoing combined valve (aortic or mitral) and coronary artery bypass surgery found a significant reduced release 
in AST enzyme in favor of cold blood cardioplegia.

Ascione et al. ${ }^{(47)}$ found a significant reduced release of cardiac troponine $\mathrm{I}$ at 1 , 24, $48 \mathrm{~h}$ postoperatively in favor of cold blood cardioplegia in comparison with warm bloodcardioplegia.

Biochemical markers of myocardial injury i.e. CK-MB and Troponin T, have shown better laboratory profile while using worm blood cardioplegia ${ }^{(48)}$.

Less than optimal myocardial protection with cold cardioplegia is assumed to be caused by disturbance of cardiac metabolism in response to hypothermia. Adenosine triphosphate dependent reactions are impaired and result in negative influence on membrane stability, energy production, enzymatic functions, aerobic glucose utilisa-tion, adenosine tri-phosphate generation and its utilisation, cyclic adenosine monophosphate production, and osmotic homeostasis ${ }^{(9)}$.

Postoperative echocardiography performed before discharge from the hospital shows preserved myocardial ejection fraction in both the warm and cold groups. However, preservation of normal hemodynamics and ejection fraction in the postoperative period can not by itself be introduced as evidence of adequate myocardial preservation. The ventricular subendocardium may be vulnerable to ischemia with resultant patches of subendocardial necrosis detected by muscle biopsy specimen ${ }^{(49)}$.

Hemodynamic measurements performed immediately after discontinuation of cardiopulmonary bypass were similar in the hypothermic and normo-thermic groups. This is not unexpected, as the immediate period after cardiopulmonary bypass is dynamic and volatile with respect to hemodynamics. Cardiac output and blood pressure changes occur minute by minute and are influenced by volume loading, temperature changes, changing levels of anesthesia, pharmacological therapy, blood loss, and myocardial performance.

Frater and $\mathrm{Oka}^{(50)}$. randomized 23 patients undergoing coronary artery bypass grafting to either hypothermic $\left(27^{\circ} \mathrm{C}\right)$ or normothermic $\left(37^{\circ} \mathrm{C}\right)$ cardiopulmonary bypass. The 10 patients in the normothermic group had a significantly lower systemic vascular resistance that persisted into the intensive care unit. Massimino and colleagues $^{(51)}$ also observed that normothermic patients required higher doses of phenylephrine to maintain cardiopulmonary bypass pressures greater than $60 \mathrm{~mm} \mathrm{Hg}$.

From a surgical point of view, cold cardioplegia, which may be repeated every 25-30 min, may offer some advantage by allowing a longer time available for the packaging of distal coronary artery anastomoses and an operating bloodless field at the site of the anastomosis. Moreover, there was not a significant difference in the value of hemodilution at the weaning from cardio-pulmonary bypass in comparison with the administration of blood cardioplegia. On the contrary, if the surgeon prefers to use the warm cardioplegia, must pay more attention to the time of administration, being required a shorter time of repetition of the dose to achieve an effective myocardial protection during cardiac arrest.

In a large prospective randomized study, Ovrum and coworkers ${ }^{(52)}$ on 1,440 patients undergoing coronary artery bypass did not detect any difference in clinical outcome. However, the mean cross clamp time was only 34 minutes, and this could be too short to show a potential difference. The release of CK-MB form remains controversial after warm intermittent ante-grade blood cardoplegia. Pelletier et $\mathrm{al}^{(45)}$ found a lower CK-MB mass concentration after warm intermittent antegrade blood cardioplegia than after cold intermittent antegrade blood cardoplegia, but Isomura et al. ${ }^{(53)}$ found no significant CK-MB release after warm 
intermittent antegrade blood cardioplegia.

Lomivorotov $^{(54)}$ and associates reported a statistically non significant difference in cTnI release between the warm and cold groups. They studied a total of 140 patients who had valvular heart surgery with or without $\mathrm{CABG}$ under $\mathrm{CPB}$. The patients were allocated randomly to undergo either hypothermic (temperature, $31-32^{\circ} \mathrm{C}$ ) or normo-thermic (temperature $>36^{\circ} \mathrm{C}$ ) $\mathrm{CPB}$. In-hospital postoperative echocardiography and that performed at one and two months post-operatively showed preserved myocardial ejection fraction in both of their groups without any statistical significance. However, preservation of normal hemodynamics and ejection fraction in the postoperative period can not by itself be introduced as evidence of adequate myocardial preservation. The ventricular subendocardium may be vulnerable to ischemia with resultant patches of subendocardial necrosis detected by muscle biopsy specimen ${ }^{(49)}$.

Therefore preserved ventricular function after coronary bypass grafting using warm cardioplegia does not exclude limited regional myocardial damage. The study of Yau et al demonstrated increased systolic function in warm cardioplegia compared to cold cardioplegia. The difference may be attributed to a number of factors. First, warm hearts were able to increase their oxygen consumption and to use lactate as a substrate for aerobic metabolism. Second, elevated circulating catecholamines level after normothermic systemic perfusion may have a role in increasing systolic function and myocardial performance ${ }^{(32)}$.

\section{Conclusion:}

We have observed that in the presence of a complete revascularization of coronary territories, in-hospital results were not affected by the use of two different types of antegrade intermittent cardioplegia frequently used in the clinical practice to achieve the cardiac arrest during on-pump CABG.

We found that there was no difference in the clinical effect of warm or cold blood cardioplegia despite the relative increase in postoperative serum cTnI in the warm cardioplegia group. Both strategies appear to allow a comparable and satisfactory method for myocardial protection during the period of cardiac arrest. Warm blood cardioplegia requires a shorter interval of administration to achieve better myocardial protection. Therefore, the choice of one type of cardioplegia respect to each other remains at discretion of the surgeon. The statistically significant difference observed in the myocardial enzymes release in favor of cold blood cardioplegia did not translate into different clinical outcome.

\section{limitations of the study:}

Although the study was limited to a single institution, the operations included in this study were performed by multiple surgeons and therefore, lack standardization.

Intra-operative myocardial temperature was not measured during cardioplaegic arrest.

A limitation of the current study is the low number of events which precluded a multi-variable analysis for some outcomes as well as a group specific analysis with respect to the surgical procedure. Myocardial oxygen and lactate extraction and myocardial biopsy are essential markers of myocardial protection when cardioplegic arrest is used. In this study only cardiac enzyme release was used to determine myocardial injury.

\section{REFERENCES:}

1. Nicolini F, Beghi $\mathrm{C}$, Muscari $\mathrm{C}$, et al. Myocardial protection in adult cardiac surgery: current options and future challenges. Eur J Cardiothorac Surg 2003; 24:986-93. 
2. Yeatman M, Caputo M, Narayan P, et al. Intracoronary shunts reduce transient intraoperative myocardial dysfunction during off-pump coronary operations. Ann Thorac Surg 2002;73: 1411-7.

3. Khabbaz KR, Zankoul F,Warner KG. Intraoperative metabolic monitoring of the heart: II. Online measurement of myocardial tissue $\mathrm{pH}$. Ann Thorac Surg 2001; 72:S2227-33.

4. Ji B, Liu M, Lu F, et al. Warm induction cardioplegia and reperfusion dose influence the occurrence of the post CABG Tni level. Interact Cardiovasc Thorac Surg 2006; S( I ):67-70.

5. Kristian T, Joseph S. A, Allan S., Bernard R. C, Jeroen J. Bax, et al,. Fourth Universal Definition of Myocardial Infarction. The Executive Group on behalf of the Joint European Society of Cardiology (ESC)/American College of Cardiology (ACC)/American Heart Association (AHA)/World Heart Federation (WHF) Task Force for the Universal Definition of Myocardial Infarction. J Am Coll Cardiol. 2018, 72 (18) 2231-2264.

6. Abdelwahab AA, Elshora H, Arafat A. Effect of Fast Cardioplegic Arrest Induced by Adenosine on Cardiac Troponin Levels After Heart Valve Surgery. Heart, Lung and Circulation. 2018;4:1-6.

7. Lazar HI, Buckberg DG, Manganaro AJ, Becker H, Maloney JV. Reversal of ischemic damage with amino acid substrate enhancement during reperfusion. Surgery 1980;88:702-9.

8. Teoh KH, Christakis GT, Weisel RD, Frames SE, Mickle DAG, Romaschin AD, et al. Accelerated myocardial metabolic recovery with terminal warm blood cardioplegia. J Thorac Cardiovasc Surg1986;91:888-895..

9. Calafiore AM, Teodori G, Mezzetti A, Bosco G, Verna AM, Di Giammarco G, Lapenna D. Intermittent antegrade warm blood cardioplegia. Ann Thorac Surg 1995;59:398-402.

10. Zeriouh M, Heider A, Rahmanian PB, et al. Six-years survival and predictors of mortality after $\mathrm{CABG}$ using cold vs. warm blood cardioplegia in elective and emergent settings. J Cardiothorac Surg.2015;10(1): 180.

11. GoharA,ChongJP, LiewOW,denRuijterH,deKleijnDPV,SimD, et al. The prognostic value of highly sensitive cardiac troponinassaysfor adverse events inmen and women with stableheart failure and a preserved vs. reduced ejection fraction. Eur J Heart Fail 2017;19:1638-47.

12. [Baig M A, Murtaza M S, Iqbal A, Ahmad M Z, Rizvi H M, Ahmed N, Shair A, Ijaz A: Clinical outcomes of intermittent antegrade warm versus cold blood cardioplegia. J Pak Med Assoc. 2015;65(6): 593-96.

13. Jacquet LM, Noirhomme PH, Van Dyck $\mathrm{MJ}$, et al. Randomized trial of intermittent antegrade warm blood versus cold crystalloid cardioplegia. Ann Thorac Surg. 1999;67(2):471-477.

14. Sirvinskas E, Nasvytis L, Raliene L, Vaskelyte J, Toleikis A, Trumbeckaite S. Myocardial protective effect of warm blood, tepid blood, and cold crystalloid cardioplegia in coronary artery bypass grafting surgery. Croat Med J. 2005;46(6):879-888.

15. Elwatidy AM, Fadalah MA, Bukhari EA, et al. Antegrade crystalloid cardioplegia vs antegrade/retrograde cold and tepid blood cardioplegia in CABG. Ann Thorac Surg. 1999;68(2):447-453.

16. [Dar MI. Cold crystalloid versus warm blood cardioplegia for coronary artery bypass surgery. Ann Thorac Cardiovasc Surg. 2005;11(6):382-385.

17. Martin TD, Craver JM, Gott JP et al. Prospective, randomized trial of retrograde warm blood cardioplegia: myocardial benefit and neurologic threat. Ann Thorac Surg 1994 ; 57(2): 298-302.

18. Lichtenstein SV, Ashe KA, el Dalati H, Cusimano RJ, Panos A, Slutsky AS. Warm heart surgery. J Thorac Cardiovasc Surg 1991; 101(2): 269-74.

19. Christakis GT, Buth KJ, Weisel RD, Rao V, Joy L, Fremes SE et al. Randomized study 


\section{Ahmed Hassouna, et al.,}

of right ventricular function with intermittent warm or cold cardioplegia. Ann Thorac Surg 1996; 6:128-34.

20. Fan Y, Zhang A-M, Xiao Y-B, Weng Y-G, Hetzer R. Warm versus cold cardioplegia for heart surgery: a meta-analysis. Eur J Cardiothorac Surg 2010; 37(4):912e9.

21. Mallidi HR, Sever J, Tamariz M, Singh S, Hanayama N, Christakis GT et al. The short-term and long-term effects of warm or tepid cardioplegia. J Thorac Cardiovasc Surg 2003;125:711-20.

22. Landymore RW, Marble AE. Effect of hypothermia and cardioplegia on intramyocardial voltage and myocardial oxygen consumption. Can J Surg 1989; $32: 452-6$.

23. Loop FD, Higgins TL, Panda R, Pearce G, Estafanous FG. Myocardial protection during cardiac operations. Decreased morbidity and lower cost with blood cardioplegia and coronary sinus perfusion. $\mathbf{J}$ Thorac Cardiovasc Surg. 1992;104(3):608618.

24. Martin TD, Craver JM, Gott JP et al. Prospective, randomized trial of retrograde warm blood cardioplegia: myocardial benefit and neurologic threat. Ann Thorac Surg 1994 ; 57(2): 298-302..

25. Mauney MC., and Kron IL., The Physiologic Basis of Warm Cardioplegia. Ann Thorae Surg, 1995;60:819-23.

26. Ikonomidis JS., V Rao, R D. Weisel, N Hayashida, and $\mathrm{T}$ Shirai. Myocardial Protection for Coronary Bypass Grafting: The Toronto Hospital Perspective. Ann Thome Surg 1995;60:824-32.

27. Singh, A.K., Bert, A.A., Feng, W.C., and Rotenberg, F.A. Stroke during coronary artery bypass grafting using hypothermic versus normothermic perfusion. Ann Thorac Surg.1995;59:84-89.

28. Craver, J.M., Bufkin, B.L., Weintraub, W.S., and Guyton, R.A. (1995) Neurologic events after coronary bypass grafting: further observations with warm cardioplegia. Ann Thorac Surg. 59, 14291433.
29. Sirvinskas E, Nasvytis L, Raliene L, Vaskelyte J, Toleikis A, Trumbeckaite S. Myocardial protective effect of warm blood, tepid blood, and cold crystalloid cardioplegia in coronary artery bypass grafting surgery. Croat Med J. 2005;46(6):879-888. .

30. Franke UFW, Korsch S,Wittwer T, et al. Intermittent antegrade warm myocardial protection comparedto intermittent cold blood cardioplegia in elective coronary surgery: do we have to change?Eur J Cardiothorac Surg 2003;23:341-6.

31. Boldt J, Knothe C, Welters I, et al. Normothermic versus hy 7 pothermic cardiopulmonary bypass: do changes in coagulation differ? Ann Thorac Surg 1996; 62:130-5.

32. Yau TM, Carson S, Weisel RD, et al. The effect of warm heart surgery on postoperative bleeding. J Thorac CandiovascSurg 1992; 103: 1155-63

33. Vaughn CC, Opie JC, FT Florendo, PA Lowell, J Austin Warm blood cardioplegia. Ann Thorac Surg, 55 (1993), pp. 12271232]

34. Tönz M., Mihaljevic T., von Segesser L.K., Schmid E.R., Joller-Jemelka H.I., Pei P., et al. Normothermia versus hypothermia during cardiopulmonary bypass: a randomized, controlled trial. Ann Thorac Surg. 1995;(59): pp. 137-143.

35. Yau TM, Weisel RD, Mickle DAG et al. Vitamin E for coronary bypass operations. A prospective, double-blind, randomized trial. J Thorac Cardiovasc Surg 1994; 108(2): 302-10.

36. Calafiore AM, Teodori G, Bosco G, Di Giammarco G, Vitolla G, Fino C, et al. Intermittent antegrade warm blood cardioplegia in aortic valve replacement. J Card Surg. 1996;11:348-54

37. Abah U, Garfjeld Roberts P, Ishaq M, De Silva R. Is cold or warm blood cardioplegia superior for myocardial protection?. Interact Cardiovasc Thorac Surg. 2012; 14(6):848855.

38. Boening A, Assling-Simon L, Heep M, Boengler K, Niemann B, Grieshaber P. 
Buckberg's blood cardioplegia for protection of adult and senile myocardium in a rat in vitro model of acute myocardial infarction. Exp Gerontol. 2018;104:98-104.

39. Onorati F, Santini F, Dandale R, et al. "Polarizing" microplegia improves cardiac cycle efficiency after CABG for unstable angina. Int J Cardiol. 2013;167(6):2739-2746.

40. Hayashida $\mathrm{N}$, Isomura $\mathrm{T}$, Sato $\mathrm{T}$ et al. minimally diluted tepid blood cardioplegia. Ann Thorac Surg 1998; 65(3): 615-21.

41. Guru V, Omura J, Alghamdi AA, Weisel R, Fremes SE. Is blood superior to crystalloid cardioplegia?: A meta-analysis of randomized clinical trials. Circulation 2006; 114(1 Suppl): I-331.

42. Bruyn H De, Gelders F, Gregoir T, et al. Myocardial Protection during Cardiac Surgery: Warm Blood versus Crystalloid Cardioplegia. World J Cardiovasc Dis. 2014;04(09):422-

431.doi:10.4236/wjcd.2014.49053..

43. Hilton CJ, Teubl W, Acker $\mathrm{M}$, et al. Inadequate cardioplegic protection with obstructed coronary arteries. Ann Thorac Surg 1979;281:323-34.

44. Matsuura, H., Lazar, H.L., Yang, X.M., Rivers, S., Treanor, P.R. and Shemin, R.J., Detrimental effects of interruption warm blood cardioplegia during coronary revascularization. Journal of Thoracic and Cardiovascular Surgery, 1993; 106: $357-$ 361.

45. Pelletier LC, Carrier M, Leclerc Y, Cartier R, Wesolowaska E, Solymoss BC. Intermittent antegrade warm versus cold blood cardioplegia: a prospec tive, randomized study. Ann Thorac Surg 1994;58:41-8

46. Kaul, T. K., al Khadimi, R., Sharif, H. \& Ramsdale, D. R. Results of combined valve replacement and myocardial revascularization. Relation to method of myocardial protection. J. Cardiovasc. Surg. 30, 322-327 (1989).

47. Ascione R, Caputo M, Gomes WJ et al. Myocardial injury in hypertrophic hearts of patients undergoing aortic valve surgery using cold or warm blood cardioplegia. Eur J Cardiothorac Surg 2002; 21(3):440-6.

48. Minatoya K, Okabayashi H, Shimada I, Tanabe A, Nishina T, Nandate $\mathrm{K}$ et al. Intermittent antegrade warm blood cardioplegia for CABG: extended interval of cardioplegia. Ann Thorac Surg 2000; 69:74-6.

49. Rosenkranz ER, Okamoto F, Buckberg GD, Robertson JM, Vinten-Johansen J, Bugyi HI. Safety of prolonged aortic clamping with blood cardioplegia. III. Aspartate enrichment of glutamate blood cardioplegia in energy-depleted hearts after ischemic and reperfusion injury. J Thorac Cardiovasc Surg 1986; 91:428-35.

50. Frater RWM, Oka Y. Endocrine response to extracorporeal circulation. In: Hagl S, K. Loverkorn WP, Moyr N, Sebening F, eds. Thirty years of extracorporeal circulation. Munich: Deutches Hezzerntrimy, 1985: 297-312.

51. Massimino RJ, Steams GT, Gough JD, Martin J. Singh AK. Moderate hypothermic versus normothermic total cardiopulmonary bypass for coronary artery surgery: a retrospective study. J Extra-Corpor TechnoI 1991; 23: 5-8

52. Øvrum E, Tangen G, Tølløfsrud $S$, et al. Cold blood cardioplegia versus crystalloid cardioplegia: a prospective randomized study of 1440 patients undergoing coronary artery bypass grafting. J Thorac Cardiovasc Surg 2004;128:860-5. 10.1016/j.jtcvs. 2004.03.032.

53. Isomura T., Hisatoni, K., Sato, T., Hayashida, N. and Ohiski, K., Interrupted warm blood cardioplegia for coronary artery bypass grafting. European Journal of Cardiothoracic Surgery, 1995, 9, 133-138.

54. Lomivorotov VV, Shmirev VA, Efremov SM, Ponomarev DN, Moroz GB, Shahin DG, Kornilov IA, Shilova AN, Lomivorotov VN,Karaskov AM. Hypothermic versus normothermic cardiopulmonary bypass in patients with valvular heart disease. J Cardiothorac Vasc Anesth. 2014 Apr;28(2):295-300. 


\title{
شلل القلب البارد مقابل الدافئ لحماية عضلة القلب أثناء عمليات ترقيع الثرايين التاجية
}

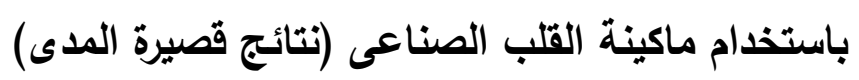

أ.د. أحمد حسونة(1)، أ.د. أحمد عبد العزيز (1)، أ.د. أيمن محمود عمار (1)

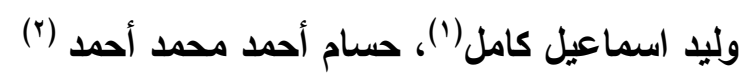 \\ (1) قسم جراحة القلب والصدر ، كلية الطب، جامعة عين شمس،
}

المقدمة: يعتمد الحصول على نتيجة جراحية مثالية على إجراء عملية جراحية تتسم بالكفاءة الثقنية مع حماية القلب التباء

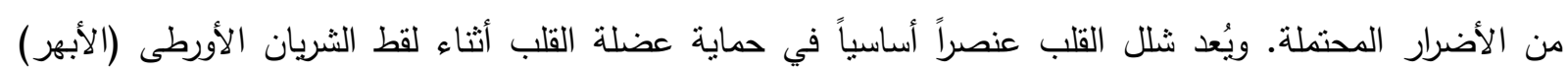

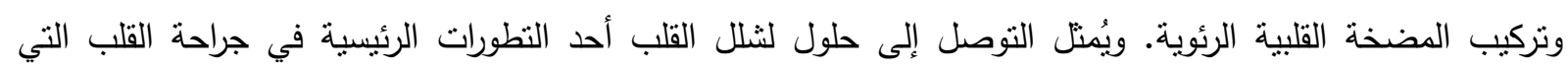

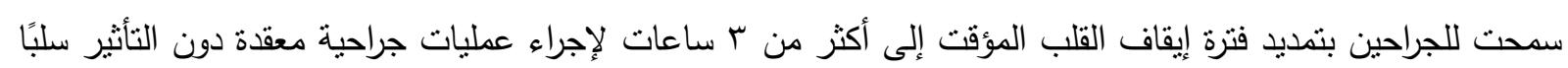
على وظيفة عضلة القلب.

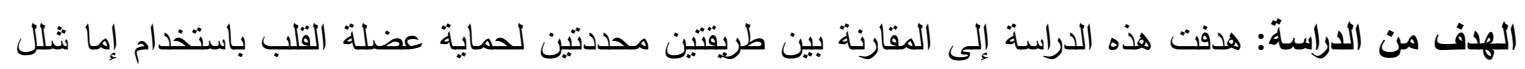
القلب الدموى البارد المنقطع أو الثنلل القلبي الدموى الدافئ المتقطع.

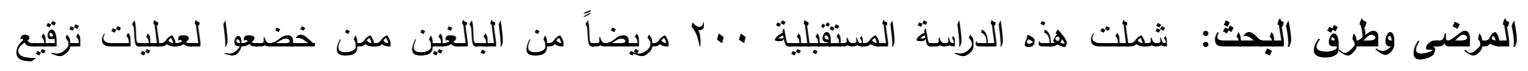

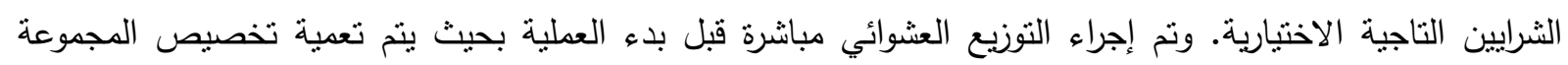

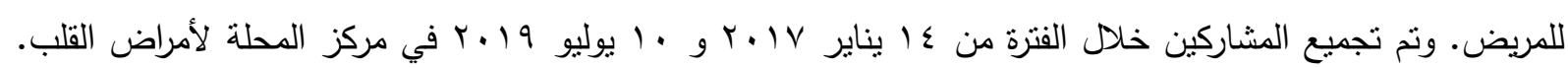

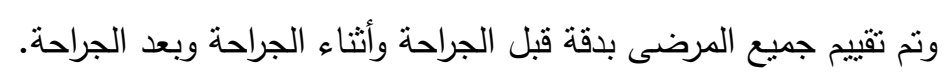

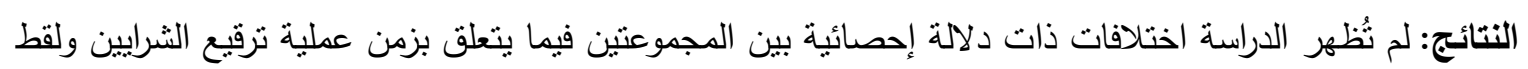

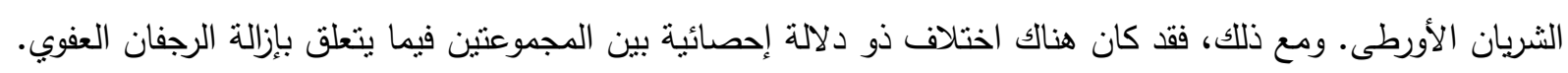

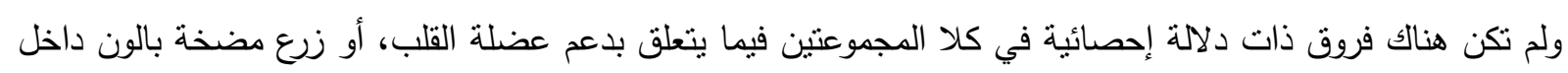

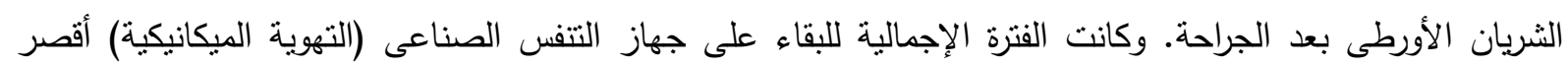
إحصائيًا في المجموعة الدافئة مقارنة بالمجموعة الباردة.

الخلاصة/الاستتاج: نوصلت الدراسة إلى عدم وجود فرق في الثأثير السريري لثنل القلب في الدم الدافئ أو البارد

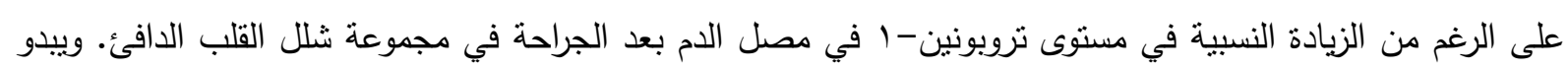
أن كلتا الاستراتيجيتين تسححان بطريقة مرضية وقابلة للمقارنة لحماية عضلة القلب خلال فترة السكتة القلبية المؤقتة. 